\title{
RESISTING WRONGFUL EXPLANATIONS
}

\author{
Arianne Shahvisi
}

$\prod$

N THE 2017 series of the UK reality television show The Apprentice, a group of women discussed a sales strategy for maximizing the revenue of their burger stand in London's financial sector. Celebrity businessperson Karren Brady eavesdropped on their conversation. One contestant remarked that since the financial sector is male dominated, they should make sure that the team members chosen to sell the food are "attractive." Here, Brady cut in: "What do you mean about attractive?" The contestant, now more tentatively, responded that the salesperson must be "good at selling and ... they have to be good to sell to men, if you see what I'm saying." Brady pressed her: "No, I don't know what you're saying. What are you saying?"1 The team of hopefuls fell silent, Brady's feigned misunderstanding of a widely understood and commonly used sexist sales strategy hanging in the now charged air. They all knew what the contestant was saying, and they knew Brady understood and was pretending not to. To explain would be to bring the sexism into the open, to commit to its assumptions, and to admit to having suggested that those assumptions be capitalized on and thereby entrenched. The contestant, precisely because Brady refused to understand, was made to confront the fact that her comment was ethically dubious.

In this paper, I develop and endorse a generalized version of the tactic of epistemic resistance that Brady deployed to expose and disarm the contestant's sexism. In doing so, I draw on the work of Gaile Pohlhaus Jr., who shows that imploring marginalized people to understand marginalizing practices amounts to a request that they legitimize their own oppression. ${ }^{2}$ I expand on Pohlhaus's analysis in two novel ways. First, I rehearse what it is to understand by exploring its association with explanation. Using Van Fraassen's and Achinstein's pragmatic theories of explanation, I describe explanations as answers to why-questions and as speech acts whose success depends on the explainee revising her background

1 Scott Bryan, "Karren Brady Shut Down a Sexist Comment on 'The Apprentice' and It's Great," BuzzFeed, October 5, 2017. https://www.buzzfeed.com/scottybryan/none-of-you -strike-me-as-shy.

2 Pohlhaus, "Wrongful Requests and Strategic Refusals to Understand." 
assumptions as directed by the explainer. ${ }^{3}$ The revision to the explainee's background assumptions sometimes requires the acceptance of generalizations that are ethically and epistemically troubling. In those cases, the explanation should be blocked. I advocate a variety of explanatory resistance in which the explainee feigns misunderstanding to corner the explainer into exposing or retreating from the false, harmful assumptions upon which their explanation depends. I call this strategy "disunderstanding."

Second, I situate this strategy within Fricker's epistemic injustice schema as a response to what I call "explanatory injustice," emphasizing the fact that marginalized people are not able to participate fully in the construction of explanations and are liable to be harmed by wrongful explanations. ${ }^{4}$ I conclude that we should be more cognizant of the way power and marginalization delimit the epistemic terrain, and be prepared to undertake resistance in order to uncloak the ensuing ethical and epistemic shortcomings.

\section{STRATEGIC REFUSALS TO UNDERSTAND}

Conventional wisdom has it that attempting to understand others and follow their reasoning is ethically and epistemically virtuous. Consider the Principle of Charity, whose observance is often taken to be a cornerstone of courteous, productive dialogue: "We make maximum sense of the words and thoughts of others when we interpret in a way that optimizes agreement."5 Pohlhaus shows that, in certain contexts, refusing to understand can be ethically and epistemically preferable. She focuses on situations in which members of oppressed groups are asked to follow the reasoning of those in privileged positions as they attempt to justify their oppressive actions. Pohlhaus shows that in such cases a listener refusing to understand can be a form of resistance, an invitation to a more productive interaction, and a way of bringing oppressive beliefs "out of the background and to the fore." ${ }^{6}$ This is ethically productive since it combats oppressive ideologies, and is epistemically productive because it demands the rejection or revision of false or misleading assumptions.

Pohlhaus's argument is elucidated via an example. She draws on the work of Patricia Williams, who describes the use of buzzer systems by shop owners

3 Van Fraassen, The Scientific Image; Achinstein, The Nature of Explanation.

4 Fricker, Epistemic Injustice.

5 Davidson, "On the Very Idea of a Conceptual Scheme," 197. The principle of charity is a content-based ideal, while "civility" is primarily a tone-based ideal for productive discussion. See Shahvisi, "Privilege, Platforms, and Power," for a critique of the expectation of civility.

6 Pohlhaus, "Wrongful Requests and Strategic Refusals to Understand," 238. 
in New York City in the 1980 os to screen customers and refuse entry to those who were deemed to look "undesirable," where undesirability was primarily determined by race. ${ }^{7}$ The buzzer system was widely discussed and protested, but soon became standard practice in many small shops. Williams recounts the way in which the public debate was characterized by Black people being asked to understand the decisions of white shopkeepers and retail assistants. She refers to a letter to the New York Times whose white authors ask Black readers to admit that they too would exclude themselves. She refers to the "repeated public urging that blacks put themselves in the shoes of white store owners, and that, in effect, blacks look into the mirror of frightened whites [sic] faces to the reality of their undesirability; and that then blacks would 'just as surely conclude that [they] would not let [themselves] in under similar circumstances.","

This case raises serious ethical and epistemic issues. Williams, and other Black people, are asked to join racist shopkeepers in rejecting themselves and accepting lines of reasoning that position them as violent and threatening in order to present racial profiling as justifiable. Williams qua Black person is urged to understand herself as a person who should be excluded as dangerous. Her understanding may be taken as an admission: I can reasonably be categorized as that sort of person; your response is appropriate. As such, she is being asked to cooperate in perpetuating a falsehood. That is the epistemic wrong.

The ethical wrong that is committed in requesting her understanding consists in the demand that she cooperate in the suppression of her subjectivity by limiting her range of action and by foreclosing the option of calling out the harm perpetuated by the understanding. If Williams agrees to understand the debate as it is presented, she must concede that she looks like a dangerous person who induces such fear in others that they cannot reasonably be asked to share enclosed public spaces with her and that she is automatically such a person by virtue of being Black. To accede to this is to limit her own epistemic possibilities. For if she agrees that it is acceptable to stereotype her and exclude her, she and other Black people are thereby hindered in challenging racism in this case and others. She is being asked to renounce a position from which she can criticize any subsequent harms, since understanding the racist assumptions would also imply an understanding of any actions premised on them. Further, consenting to be interpreted as an instance of a stereotype would mean relinquishing something of the individual agency that is required to participate meaningfully in the epistemic community. As Pohlhaus says:

8 Williams, "Spirit-Murdering the Messenger," 129, brackets in original. 
Persons are being called to understand something that only makes sense from within patterns and practices that hold oppressive power relations firmly in place and that actively prevent those asked to understand from calling attention to this fact.... In these cases, demonstrating the harm that the requested understanding does can only be done from worlds that actively resist the sense of the world one has been implicitly asked to inhabit. $^{9}$

These examples demonstrate that the request that one understand can be constitutive of the marginalization one is being asked to understand. In these cases, the person who requests that the listener understand thereby wrongs the listener. And a marginalized person may not have the luxury of refusal; refusing to signal assent could escalate into more immediate harms. Yet agreeing to understand entails complicity, since the hearer is asked to join the speaker in recognizing the acceptability or inevitability of the oppressive claims, thereby entrenching their acceptability. ${ }^{10}$ One might describe this as a request that the listener internalize the oppression by affirming a negative self-perception of automatic wrongdoing, leading to reduced agency. ${ }^{11}$ There is a double bind.

Pohlhaus's examples are not exceptional; they belong to a broader trend of requests for understanding that entreat the listener to accept oppressive assumptions. These requests need not be made of members of oppressed groups in order to be wrongful, though they are clearly more wrongful, and wrongful in a way that is more liable to cause harm, where the request to understand a form of oppression is made of a person whose oppression takes that form. Any request that oppressive assumptions be accepted presents ethical and epistemic concerns, and this paper considers listeners of all positionalities, since the responsibility for justice falls to all of us.

Wrongful requests for understanding are not rare. In conversations in which marginalizing comments are made, speakers typically deploy common expressions that enjoin the listener to see the sense and obviousness of what is being said and to offer comprehension (e.g., "put yourself in the shoes of"; "you have to understand that"; "surely you can see that"; "it goes without saying that"; "you know what I mean"). Consider this excerpt from a 2009 television appearance of us Fox News presenter Brian Kilmeade:

Pohlhaus, "Wrongful Requests and Strategic Refusals to Understand," 231-32.

This complicity is best understood as attributability, rather than accountability, in the sense described by Zheng in "Attributability, Accountability, and Implicit Bias."

Liebow, "Internalized Oppression and Its Varied Moral Harms"; Bartky, Femininity and Domination. 
I asked [a Muslim] one time ... "How do you feel about the extra scrutiny, clearly, you're getting at the airports?" And he said, "I'm all for it, because I want to get home to my family, too." And that's really got to be the attitude. So, if you're Islamic, or you're Muslim and you're in the military, you have to understand ... and that's just the fact right now in the war that was declared on us. ${ }^{12}$

Kilmeade requires that Muslims understand their racial profiling and, further, that they accordingly have the "right" attitude toward it - that is, one of acceptance and empathy with the assumptions underwriting the practice. Having the "right attitude" is a request for affective labor as well as understanding. Not only must oppressed people understand the oppressive practice, but they must also signal approval and strive to ensure that others do not feel bad about their (support for) oppressive behavior. Racial profiling is a common occasion for wrongful requests for understanding, where "safety" and "security" are taken to be concerns whose primacy one cannot reject without seeming unreasonable and reckless, even though the benefits and burdens are clearly unevenly distributed. Consider that more than half of British people support the racial profiling of (those who appear to be) Muslims or Arabs for "security" reasons. ${ }^{13}$ Those who are targeted are expected to prioritize this abstract notion of security even though doing so imperils their own more tangible personal security and comfort and that of other people of color.

In a similar way, Daily Mail columnist Max Pemberton invokes understandability in his appraisal of a man who murdered his own wife and daughter:

Of course, such men are often motivated by anger and a desire to punish the spouse.

But while killing their partner as an act of revenge may be understandable, for a man to kill his children (who are innocent bystanders in a marital breakdown) is a very different matter.

I believe it is often a twisted act of love, as the man crassly believes that the crisis in their lives is so great that the children would be better off dead. ${ }^{14}$

As feminist writer Laura Bates notes, Pemberton not only suggests that the murder of a wife may be "understandable" but also goes on to normalize the ics added. 
act by distancing it from the murder of the daughter, which is a "very different matter" since she is, by contrast, "innocent." 15 Even so, the killing of the child is described as an "act of love," if a "twisted" one, that is hypothesized to protect children from "crisis in their lives." Pemberton urges us to see that both killings are understandable, provided one is charitable in considering the point of view of the killer.

In cases such as these, in which one is faced with a wrongful request for understanding, Pohlhaus argues that it is ethically and epistemically productive to strategically withhold comprehension. Such refusals are already in operation, as evidenced by Brady's feigned misunderstanding in the opening example. My aim in the rest of this paper is to further analyze and systematize these forms of resistance. I begin by examining what is meant by "understanding" through a study of its relationship to explanation.

\section{EXPLANATION, UNDERSTANDING, AND INJUSTICE}

Wrongful requests for understanding are more easily identified and blocked if we have a clearer sense of what it means to understand. In this section, I explore pragmatic conceptions of explanation, which draw on the relationship between explanation and understanding, and then consider the ways in which explanations can be unjust. This lays the groundwork for the account of strategic refusals to understand that I introduce in section 3 .

\subsection{Understanding as an Effect of Explanation}

Successful explanations impart understanding, and a person who does not understand is a person who lacks an (adequate) explanation. ${ }^{16} \mathrm{~A}$ wrongful request for understanding is therefore a request that a wrongful explanation be accepted. But what is an explanation? Since I am addressing a problem relating to the everyday use of explanations and understanding in particular social contexts, a pragmatic account of explanation is most apt. Pragmatic, or "contextual," accounts of explanation are concerned with the use of explanations and the role of contextual factors, such as background knowledge and interests, in determining explanatory success. I explore a synthesis of two prominent pragmatic theories

15 Bates, "A Cycle of Violence." Note that family annihilators - men who murder their families immediately prior to killing themselves - are chillingly common. In the US, these incidents occur as often as once a week (Manne, Down Girl).

Khalifa, "Inaugurating Understanding or Repackaging Explanation?"; Strevens, "No Understanding without Explanation." Though it will not be important for the purposes of our inquiry here, note that there is a lively literature on the relationship between scientific explanations and understanding (De Regt, "Understanding and Explanation”). 
of explanation: that of Van Fraassen and that of Achinstein. ${ }^{17}$ Examining these theories offers insights as to how to conceive of, and disrupt, understanding.

One of the most well-known pragmatic accounts of explanation is given by Van Fraassen, who describes a demand for explanation as a particular kind of question, and an explanation as an adequate answer to that question, which dispenses with the explainee's original explanatory demand by delivering the understanding that was sought. Though they are not always immediately framed as such, explananda can be read as contrastive "why-questions." That is, a request for explanation can be expressed in the following form: Why event $P_{k}$ (the explanandum ) rather than any of the alternative events in its contrast class $X\left(P_{1}\right.$, $\left.P_{2}, \ldots P_{n}\right)$ ? The contrast class enumerates all the other possible events that could have obtained instead of $P_{k}$. Context is critical. There are many different ways of forming the contrast class, depending on what precisely is being asked. If I see some children hitting another child in the street and say "Hey, what's going on here?" this is a demand for explanation that contains the why-question "Why are you hitting that child?" and the contrast class "rather than playing with her, leaving her alone, etc." The children must assess the context of the situation in order to ascertain that this is the contrast class I intend, and answer appropriately. They might get the contrast class wrong and say "What, you think we should kick her instead?"

Context also features in the kind of explanation that is requested. Explainers must take note of the "relevance relation" $R$, which encompasses other contextual factors that are relevant to providing an adequate answer. In the example above, the children must work out what kind of explanation I am asking for. They will likely assume that I am referring to the hitting, that I think that (unjustified) hitting is wrong and surprising, and that they ought therefore to attempt to justify the hitting, with reference to some causally relevant event ("She said something racist"), or to stop doing it in an attempt to evade the explanatory demand. If they get the relevance relation wrong, by making incorrect assumptions about my background knowledge, they might offer an explanation that is unsatisfactory-for example, "It was our turn" or "It's the first day of the month." ${ }^{8}$

One asks "Why $P_{k}$ ?" when $P_{k}$ is surprising, because one expected another possible state of affairs instead. That surprise is typically the result of the explainee having incomplete, inadequate, or false information relating to the occurrence of $P_{k}$. Accordingly, the explanation furnishes the explainee with information that renders $P_{k}$ unsurprising, or even expectable. Therefore, to explain an event

17 Van Fraassen, The Scientific Image; Achinstein, The Nature of Explanation.

18 A British folk ritual involves starting the month by declaring "a pinch and a punch for the first day of the month!” while pinching and punching someone. 
is to show that "given the particular circumstances and the laws in question, the occurrence of the phenomenon was to be expected; and it is in this sense that the explanation enables us to understand why the phenomenon occurred." ${ }^{19}$

Making an explanandum expectable is the central function of an explanation. An explanation is requested when a particular occurrence seems unusual or surprising relative to an extant set of background assumptions; explaining eliminates that surprise by providing additional information that causes the explainee to revise her assumptions, making the occurrence seem ordinary. Therefore, "a (good) explanation raises or makes high its explanandum's probability, $p$; and the more it does so (ceteris paribus) the better it is." ${ }^{20}$ Explanations therefore convert surprising facts into unsurprising facts by modifying the auxiliary assumptions of the explainee.

A second pragmatic theory of explanation is Achinstein's description of explanations as "illocutionary acts." 21 This term was coined by Austin, who described speech acts as utterances that not only provide information but also do something. Austin distinguishes three kinds of speech acts. A "locutionary" act is simply the action of making a meaningful utterance (e.g., "You upset me"). An "illocutionary" act is the action that results from the utterance, which in the case of "You upset me" is the action by which the speaker informs the hearer of the effects of their behavior. A "perlocutionary" act is the effect of the utterance, which in this case might be to induce feelings of guilt or regret. In Austin's words:

Saying something will often, or even normally, produce certain consequential effects upon the feelings, thoughts, or actions of the audience, or of the speaker, or of other persons: and it may be done with the design, intention, or purpose of producing them.... We shall call the performance of an act of this kind the performance of a perlocutionary act or perlocution. $^{22}$

While illocutionary acts focus on the function of the utterance, perlocutionary acts describe its effects. Asking "Is anyone else cold?" is on the face of it a statement about a person's own temperature and a question about the temperature of those in the room, but it can also perform the illocutionary act of requesting permission to raise the temperature of the thermostat and might have the perlocutionary effect of someone feeling obliged to offer you their jumper.

According to Achinstein's theory, to explain is to do something. Explanations

Hempel, Aspects of Scientific Explanation, 337, italics in original.

Mellor, "Probable Explanation," 232.

Achinstein, The Nature of Explanation.

Austin, How to Do Things with Words, 101. 
are therefore illocutionary acts: explainers set out to do something when they offer explanations. ${ }^{23}$ They intend to make something understandable, to answer a question, to make the explanandum less surprising. Yet this analysis can be taken further than Achinstein does, since explanations are also perlocutionary acts. Recall that on Van Fraassen's theory explanations answer why-questions. They do so by reconfiguring the background assumptions of the explainee in order to make the explanandum expectable. But, crucially, as I will explore later, that process is one over which the explainee exercises influence.

In a similar vein to Van Fraassen's contrast class and relevance relation, which summarize the contextual information that is necessary to providing a successful explanation, Achinstein distinguishes the "goodness" of explanations from their "correctness." A correct explanation is one whose propositional content is true; a good explanation is one that is appropriate given the background knowledge and interests of the explainee. Consider that "because of the initial conditions of the universe plus the fundamental laws of nature" might seem like a reasonable causal explanation of any event, and it is most likely also a correct explanation, but it is (almost) never a good one. A correct explanation need not be good, and that determination depends on the explainee. If I explain to a layperson why grass is green by reference to the electron configuration around the molecular structure of chlorophyll, that is unlikely to be a good explanation even though it is correct. Equally, a good explanation may not be a correct one. If a child asks why the mince pie is gone and I say "Santa ate it," they are likely to take this to be a good explanation even though it is not a correct one. We must strive for goodness and correctness in our explanations.

The idea of a good explanation mirrors Austin's "felicity conditions," which must be met in order for a speech act to succeed. ${ }^{24}$ Among other things, success requires that the listener receive the utterance in the way in which the speaker intended it. This requires the speaker to pay attention to the background knowledge of the listener, but it also requires the listener to play her role in cooperatively granting uptake. Jennifer Hornsby describes "successful illocutionary acts" as those characterized by reciprocity, where interlocutors "recognize one another's speech as it is meant to be taken: An audience who participates reciprocally does not merely understand the speaker's words but also, in taking the words as they are meant to be taken, satisfies a condition for the speaker's having done the communicative thing that she intended."25 In the context of explanations,

23 By contrast, Hempel was concerned with the locutionary aspects of explanation ("Studies in the Logic of Explanation"; Aspects of Scientific Explanation).

24 Austin, How to Do Things with Words.

25 Hornsby, "Disempowered Speech," 134, emphasis added. 
the idea of "taking the words as they are meant to be taken"- or of indicating to the person explaining that their explanation was a "good" one or that your why-question has been answered-points to the important role of the listener in ensuring both that understanding goes through and that this uptake is communicated, for example, by saying "Ah, I see" or "That makes sense now," or by nodding and asking no further questions.

Taking all this together, we can see that a refusal to understand in Pohlhaus's sense amounts to a refusal to accept an explanation, which can be achieved by responding to the explanation in such a way as to block the perlocutionary act of having one's auxiliary assumptions revised in the way the explainer intends. Note that the explanation may well have made sense in some limited sense, and the explainee may well understand in some limited sense (as Brady clearly did in the Apprentice case), but the point here is that the explainee has spotted that something is ethically and epistemically amiss, and is accordingly performing the refusal as a way of encouraging the explainer, and any onlooker, to change their auxiliary assumptions. Whatever surprise motivated the explanatory demand then persists, and the explainer is obliged to switch course, hopefully giving more careful thought to their explanation.

Returning to Williams's experience of racial profiling, consider that customers wishing to enter shops are normally allowed to do so. Being refused entry, or learning one might be refused entry, is surprising and requires explanation. The explanation provides some additional information to Williams: you, by virtue of your race, are threatening, and your presence in the shop will make people uncomfortable. Williams is supposed to respond by revising her auxiliary assumptions; while she previously thought of herself as a nonthreatening person attempting to buy a gift for her mother, she must now mitigate her surprise at being denied entry to the shop by agreeing to see herself, and other Black people, as threatening. She is supposed to reason that if a person made her fearful, she too would want them to be denied admittance to a shop she was browsing or working in. The "error" that led to her not understanding and requiring an explanation was her belief that she is not a scary person, that she is an ordinary, nonthreatening person. If the explanation goes through, she stands corrected. But this revision to her auxiliary assumptions must be resisted. It cannot be right to ask a person to replace their surprise at an injustice with an acceptance that they are a person who automatically deserves to be treated unjustly. To do so is to ask them to concede that what would normally count as an injustice is not so in relation to them, on the grounds that they belong to a social group for whom that harmful treatment is deemed to be apt. We must ask what happens if Williams, or an 
onlooker, responds with "I'm sorry, I don't understand" or "What is it about me/ her that warrants this treatment?" I return to this question in section 3.

\subsection{Explanatory Injustice}

As we have seen, explanations act on and shape our beliefs, and they are context dependent and interest relative. Values unavoidably affect the explanations that are and are not requested, offered, and accepted. It is therefore important to briefly consider the operation of power in relation to explanations: who gets to explain and who is generally required to accept explanations offered by others. In this section, I describe how explanations, as a core knowledge-production activity, are related to "epistemic injustices."

Epistemic injustice occurs when people are wronged specifically in their capacities as knowers. ${ }^{26}$ To be wronged as a knower is to be wronged as a member of a community of people who generate knowledge by interpreting the world and sharing their interpretations with others. Epistemic injustice, as characterized by Fricker, comes in two varieties: testimonial injustice, which limits a person's ability to share knowledge, and hermeneutical injustice, which limits a person's ability to generate knowledge.

A testimonial injustice occurs when a person, due to identity prejudices held by listeners, has her credibility as a testifier systematically misjudged. In assessing the quality of the testimony of others, we take shortcuts based on widespread stereotypes about the social groups we believe them to belong to. Members of marginalized groups are often subject to credibility deficits and are liable not to be believed or taken seriously even when they are authorities on the topic under discussion. Conversely, members of privileged groups are often subject to credibility excesses, where they are granted authority even in relation to topics on which they have no expertise. Women experience credibility deficits relative to men, people of color relative to white people, working-class people relative to middle-class people, and nonnative language speakers relative to native speakers.

A hermeneutical injustice obtains when a group of people, due to structural prejudice in the collective interpretational resources, has some substantial part of its social experience obscured from collective understanding. They are prevented from articulating their situation by a paucity in the shared inventory of available vocabulary, conceptual frameworks, and causal models. Again, members of marginalized groups are most likely to be subject to this kind of injustice, and these lacunae can result in the inability to successfully communicate injustices that affect them particularly or overwhelmingly, which may cause distress, alienation, and cognitive dissonance, and can obstruct meaningful change. Her-

Fricker, Epistemic Injustice. 
meneutical injustice therefore limits the agency of those it affects. Consider that before the introduction of the term "sexual harassment" in the 1970s, women were unable to effectively communicate their experiences in the workplace and struggled to pursue justice against their harassers - there was simply no widely accepted concept or terminology for the wrongs committed against them. Hermeneutical injustices occur because marginalized people are also marginalized within the processes of developing concepts and terms for understanding the social world-they are rarely the toolmakers in our knowledge economy, or at least, their tools are seldom adopted by others. And while in the long term we are all epistemically impoverished by hermeneutical injustices, since understanding the social world around us is a collective good, the actual short-term burdens are not equally shared: hermeneutical injustices are "like holes in the ozone-it's the people who live under them that get burned." ${ }^{27}$

As we have seen, explanations act on the world, emphasizing, obfuscating, and reconfiguring our communal and individual background assumptions. They are key elements of knowledge exchange and are essential to testimony and interpretation. Yet, as with other kinds of knowledge exchange, knowers are variably situated with respect to the product and receipt of explanations. Some knowers hold a monopoly on the production of explanations, via both their perceived credibility and their access to platforms, while others do not have the credibility to be influential or successful explainers, may be more liable to be harmed by wrongful explanations, and may particularly suffer for the lack of communal conceptual resources that are required to explain their situation to others. Members of privileged social groups typically dominate roles in which one teaches, instructs, or advises others, and are vastly overrepresented within disciplines that permit them to influence public discourse: academia, law, science, journalism, and politics. These are the people that society accepts as most authoritative. They have greater control over the production and reproduction of mainstream explanations that determine the way in which we receive and understand generalizations about the world.

It is therefore instructive to introduce a specific form of epistemic injustice that I will call "explanatory injustice." ${ }^{28}$ Explanatory injustice combines ele-

27 Fricker, Epistemic Injustice, 161.

28 One species of explanatory injustice that has received considerable attention in recent years is "mansplaining," which refers to instances in which a man explains something to a woman, where: (a) he uses a condescending tone, and (b) she already knows about, or is positioned to know more about, the explanandum in question. Mansplaining exhibits testimonial injustice: it requires a man to have estimated his own credibility on the topic in question to be greater than his woman interlocutor's. Likewise for whitesplaining, in which a white person condescendingly explains racism to people of color. Whitesplaining and mansplaining 
ments of both testimonial and hermeneutical injustice. The act of explaining is affected by testimonial injustice, since those who are granted the platforms necessary for an explanation to be heard, and the credibility for an explanation to be believed, are generally those from privileged social groups. This tends to give members of privileged groups a monopoly on explaining. They are liable to produce and disseminate explanations that serve their own interests and agendas, or at least, they are unlikely to be able or willing to generate explanations that serve the explanatory needs of those from marginalized groups in challenging their marginalization. Accordingly, members of marginalized groups lack the conceptual resources to explain their experiences or dispute explanations that relate to them, which is a form of hermeneutical injustice. The explanations most widely and weightily circulated in our explanation economy are therefore those curated by more privileged people. The use of the word "economy" is significant: explanations compete with one another, and the victors are invariably those explanations proffered by the most dominant explainers that best fit with our extant background assumptions, as shaped by dominant explainers.

If particular groups have greater power over the creation and distribution of explanations, then explanations that favorably represent their interests are likely to gain traction and explanations that represent the interests of other groups are liable to be quashed where they contradict more popular explanations. The background assumptions that are the substrate of explanations are therefore liable to be epistemically faulty (i.e., false, superficial, or misleading) where they refer to the properties or experiences of marginalized groups. In the next subsection, I describe how the epistemic and ethical status of explanations is also undermined by the nature of the generalizations upon which they rely.

\subsection{When Explanations Go Wrong: The Trouble with Generalizations}

I have shown (in section 2.1) that explanations act on the background assumptions of the explainee. The explainee is given new information, or alerted to information she knew but did not consider relevant, in light of which her why-question is answered and she understands something she did not understand before. Explanations that relate to the social world draw on background assumptions that cite social patterns and generalizations. But things can easily go wrong, both because of the identities of those most likely to generate and distribute generalizations (section 2.2) and because of the nature of the background assumptions themselves. In this subsection, I discuss the latter.

Generalizations are the staple of the background assumptions whose revi-

provoke ire for marginalized people because they emphasize the monopoly that privileged people have over explanation and because they tend to silence and abase the listener. 
sion explanation consists in. As Langton says, if we wish to understand patterns and objects in the social world, we must look "for the regularities that reveal them in normal circumstances." ${ }^{29}$ In other words, we must look for the patterns that the object of interest is implicated in and make generalizations accordingly. We may then base our explanations on those generalizations. Yet Langton warns that things may not always be so simple, since in "abnormal circumstances things may be distorted, and the regularities we see may not reveal their natures." ${ }^{30}$

It seems that wrongful requests for understanding occur precisely in those "abnormal circumstances." In many cases, the regularities we observe do not reflect the nature of things, rather the "world 'arranges itself'- at least in part—to fit what the powerful believe." ${ }^{31}$ Explanations can cite superficial regularities and still function as good and even correct explanations. And if no further explanation is requested or offered, sometimes the superficially true regularity that is referenced is taken to be descriptive of the nature of the social objects under study.

Recall that explanatory demands can be framed as why-questions. And the answer to a why-question can also be cast as a why-question, producing a regress, where each new answer precedes the last along a causal chain. Where on that chain an explanation stops depends on the knowledge and interests of the explainer and the explainee, and not all stopping points are equal. If I ask why women, rather than men, tend to wear makeup, and I am told that women are generally more concerned about their appearance and being regarded as beautiful, that is not an incorrect answer in terms of its veracity with respect to our social world (it could be argued to be correct and good in Achinstein's sense), but it is a truncated one. That truncation is epistemically and ethically troubling because it implies something false and damaging about the nature of women. I could follow up by asking "Why are women generally more concerned about their appearance and being regarded as beautiful?" At some point, a patient, well-informed interlocutor would have to describe the objectification and sexualization of women, but we may never get there if I take the first explanation at face value. Therefore, the explainee plays a critical role in what sort of explanation is given and in whether that explanation itself needs explaining.

These harmful explanatory truncations often rely on nonquantified generalizations, also known as generics. Generics, such as "women are superficial" or "Muslims are terrorists," do not specify how many instantiations are necessary for their truth. They are often accepted even at low prevalence rates, especially

29 Langton, "Feminism in Epistemology," 142.

30 Langton, "Feminism in Epistemology," 142.

31 Langton, "Feminism in Epistemology," 140. 
in the case of "striking property generics," which pick out a property that is dangerous or considered to be particularly characteristic of members of that group. ${ }^{32}$ Generics play a central role in our communication and understanding of patterns in the world, yet we struggle to formalize their truth conditions, which is critical to their ability to mislead despite seeming correct. ${ }^{33}$ We have a tendency to erroneously interpret and evaluate quantified statements as generics (e.g., it is widely noted that people tend to accept "all ducks lay eggs" despite knowing that drakes do not, implying it has instead been taken to mean "ducks lay eggs"), and studies show that people are willing to accept generics based on prevalence levels as low as 10 percent, yet when presented with a generic, infer prevalence estimates as high as 100 percent. ${ }^{34}$ Generics are frequently used in common parlance, as they offer succinct, memorable heuristics for navigating the social world, while quantified statements can be clumsy and require greater sophistication. Indeed, infants as young as thirty months have already acquired certain generics, and generics are frequently used to teach children about the world through straightforward patterns and associations (e.g., "dogs go woof"; "boys do not cry"). ${ }^{35}$

Of the many errors in reasoning associated with generics, perhaps the most worrying is that where they attribute properties to members of a particular social group, listeners tend to essentialize that group - that is, to assume that members of that group have those properties by nature. ${ }^{36}$ Generics have false implicatures of naturalness, which Haslanger recommends be blocked via metalinguistic negation-for example, "It's harmful and misleading to say Muslims are terrorists; there are extremists in every social group. Lots of Muslim-majority states have been destroyed by Western imperialism, which pushes people toward extremism, and Muslims have been portrayed particularly unfairly by Western politicians and the media." Identifying and blocking erroneous or misleading statements in this way is important because otherwise:

Implicatures and presuppositions of this sort become part of the common ground, often in ways that are hard to notice and hard to combat,

Prasada et al., "Conceptual Distinction amongst Generics"; Leslie, "The Original Sin of Cognition."

33 Saul, "Are Generics Especially Pernicious?"

34 Leslie, Khemlani, and Glucksberg, “Do All Ducks Lay Eggs?”; Leslie and Lerner, "Generic Generalizations"; Cimpian, Brandone, and Gelman, "Generic Statements Require Little Evidence for Acceptance but Have Powerful Implications."

Graham, Nayer, and Gelman, "Two-Year-Olds Use the Generic/Nongeneric Distinction to Guide Their Inferences about Novel Kinds." 
and they become the background for our conversations and our practices. Once the assumption of, e.g., women's submissive nature has been inserted into the cultural common ground, it is extremely difficult and disruptive to dislodge it....

It is not the case that women are submissive, even if most women are submissive, in fact, even if all women are submissive, because submission is no part of women's nature. ${ }^{37}$

Most explanations are built on generalizations, some of which falsely imply the innate, immutable natures of particular social groups. In particular, when racism or sexism are questioned, explainers are liable to use generalizations that cite the purported properties of particular groups (e.g., "Black people are dangerous"; "women are better at child-rearing"). Generics are not the only troubling generalizations, and quantified generalizations can be just as concerning (e.g., "most men are bad at cleaning"). Generalizations of all kinds have the persuasive advantage of referring to what is immediate and simple rather than distant and complex, and they therefore benefit from the tyranny of the face value. Consider how Ockham's razor-which is informally encouraged as a heuristic in the practice of science and medicine, and is sometimes referred to in everyday conversationdirects us toward the explanation that draws on the simplest hypothesis, which usually means the one that is most parsimonious in its assumptions. One might crudely apply this principle to erroneously conclude that the reason a disproportionate number of Black people have died from coronavirus is because they have some genetic susceptibility, rather than because of the complex, interlocking determinants of health in a racist society. Our proclivity for simplicity must be closely scrutinized. Indeed, it has been demonstrated empirically that explainees prefer explanations that draw on relationships that are stable across changing circumstances, which might be taken to be a preference for explanations that rest on stereotypes. ${ }^{38}$ Moreover, generics and other generalizations are often not, strictly speaking, false, even if their implicatures are. This leads to the worrying realization that explanations can go wrong even without the construction of outright falsehoods or any violation of the rules of explaining, so that correct explanations can nonetheless be misleading and can lead to the entrenchment of incorrect assumptions. The explanatory process is itself warped by the substrate of assumptions of the explainer and explainee, either deliberately or incidentally.

Strategic refusals to understand must be attentive to these errors of reasoning and cognizant of the opportunities presented by the collaborative nature of ex- 
planations in exposing and disarming harmful assumptions. In the next section, I suggest one such strategy.

\section{EXPLANATORY RESISTANCE: THE CASE FOR DISUNDERSTANDING}

According to the pragmatic theories of explanation described in section 2.1, an explanans that does not explain is not an explanation. Importantly, the explainee is the primary adjudicator of whether the explanation succeeds. The process of explanation is therefore collaborative and dynamic, and the explainee plays a key role in the negotiation and its results. As such, the explainee might subvert this role as a way of resisting explanations that are morally troubling. Rejecting the explanans preserves the explanatory burden on the explainer, forcing her to elaborate or provide another explanans.

What I am describing does not amount to misunderstanding the explainer. A misunderstanding is a genuine failure to understand. In cases of interest, the listener is capable of understanding by accepting the explanation at face value with respect to the social norms with which it is offered, but refuses to do so, since the request for understanding and the agreement to understand are wrongful. The explanation may be a good one in Achinstein's sense (and it may even be correct in some superficial sense), but it is not a good one in an ethical or epistemic sense. Consider that when a racist or sexist joke is made, the joke is usually well understood even by those who find it morally troubling —indeed, they may not be able to see why it is morally troubling unless they understand it - to the extent that they may see why it is funny or might find it funny in spite of their awareness of its harms. ${ }^{39}$ As Bergmann says, "Being aware of a [racist or sexist] belief is not the same as holding it." ${ }^{40}$ A person can understand, but wish they did not. Misunderstanding therefore does not adequately capture the deliberate maneuver that I am recommending; the explainee understands, but strategically pretends not to. One must understand in order to pretend not to, so that the tactic of strategic refusal I am describing is only available to those who see the sense of the explanation relative to the social world we live in but want to reconfigure that world so that it has greater epistemic and ethical integrity.

Let us instead refer to the form of resistance under study as "disunderstanding" (a portmanteau of "deliberate" and "misunderstanding"). An explainee disunderstands when she feigns ignorance by pretending that a good explanation in Achinstein's sense is a bad explanation, thereby preserving the explanatory demand, or by producing a novel feigned explanatory demand in relation to a 
troubling action or utterance. Disunderstanding demands an interrogation of explanations that are ethically and epistemically troubling. It urges the explainer to expose the dubious assumptions underwriting their explanation. The rejection can take various forms: an outright refusal to accept the revision to background assumptions ("No, I don't get what you mean by 'America for Americans."); the conversion of the explanation into a new explanandum ("But why do you think that searching Muslims will make you safer?"); an articulation of unexpected surprise in response to an utterance or action that is normally taken as unsurprising ("Why did you expect your wife to adopt your surname?"); or an interrogation of the wrongful surprise of others ("Why would you assume I [a person of color] like spicy food?").

Explanations for marginalizing actions or perspectives often rely on vague, euphemistic phrases (e.g., "we need to take back control"; "we're losing our family values"). These phrases can act, without the need to say anything overtly troubling, as dog whistles that resonate strongly with those receptive to particular ideologies. Disunderstanding tries to force explainers to meet the explanatory demand by asking them to explicitly state what lies beneath their explanation, thereby exposing those ideologies, which leaves their harmful assumptions vulnerable to direct critical attention. ${ }^{41}$ As Saul says in relation to challenging generics, we need to "press people to spell out their evidence for their generic claims and to reflect on what that evidence really does or doesn't warrant." ${ }^{42}$

Let us return to Patricia Williams's experience of being refused entry to a shop on account of being Black in order to see how this might work in practice. Imagine I have observed this refusal and decide to challenge the shopkeeper:

Why didn't you let her in?

We have a buzzer system so we can keep our customers safe.

What made you think she was a threat to our safety?

Well, we've been told to not let certain kinds of people in.

What kind of people?

People who look like they might cause trouble.

You only got a quick glance at her. What was it about her that made you think she would cause trouble?

It is similar to the strategy of "pedantry" that Elisabeth Camp recommends to disrupt troubling insinuations ("Insinuation, Common Ground, and the Conversational Record").

Saul, "Are Generics Especially Pernicious?" 14. 
And so the regress goes on, and the shopkeeper (assuming they are reasonably cooperative in this exchange and do not instead turn nasty or refuse to discuss the matter) is cornered toward an ever more uncomfortable position of feeling rumbled and forced to grapple with their own assumptions or those of their managers.

Disunderstanding already happens, and its results are mixed. In the ideal case, the explainer sees a couple of moves ahead, spots their troubling assumptions, and recants them, or falls silent, feeling checkmated. This is what happened in the Apprentice example that opened the paper. Often, people become defensive and withdraw from any meaningful discussion, or they become aggressive, as is so often the case in online discussions. Even then, an important intervention has often been made from which onlookers may benefit, and the troll may be deterred in the future. Some people do not spot the trap or their moral failings and are happy to follow their troubling assumptions all the way down. In those cases, one can only hope for a more astute witness to benefit from the intervention, but there can still be value in informing the explainer of their shortcomings.

One might wonder whether it is more effective to simply say "that is racist/ sexist" rather than opting for this playful strategy. There are certainly situations in which that would be more appropriate. If a student were to make a blunt, runof-the-mill racist comment, or use an obviously racist phrase, it would be more apt to cut them down with a comment like "that is racist and we do not tolerate racism in this classroom" (with the offer to talk them through this in private after class) rather than to painstakingly tease out their assumptions while other students are potentially harmed by the ambiguity in the instructor's position and strategy. Disunderstanding should be reserved for cases in which the process of realization will be valuable to the explainer and any onlookers, and where taking that route is likely to result in a more robust and self-directed reevaluation of their position. If a student makes a more complex or obscure racist or sexist statement or insinuation, as is more commonly the case, it would be more educational to use disunderstanding to show them and their peers where they have gone wrong, rather than to merely tell them. If they spot their error before the instructor names it, they are less likely to feel humiliated or become defensive.

The same holds for cases outside the classroom: disunderstanding is generally the wrong tool to deal with direct, violent, intentionally hateful acts and the people who commit them, but it is a powerful way of helping people to spot a moral shortcoming (or cornering them into seeing one as such) and allowing them to follow the reasoning that will help them to call out the wrong in others. Ironically, disunderstanding, as opposed to merely condemning, might help people to understand their wrongdoing, which is a more robust way of en- 
couraging change. Further, if the wrongful explanation proceeds via a generic, say, "women care about how they look," it might seem opaque or irrelevant to counter it with "that is sexist" and it would appear more false to say "no, they do not," because in many cases, they clearly do. In this sense, disunderstanding can function as a dialogic form of metalinguistic negation, in which the explainee's prerogative to determine whether an explanation answers the why-question (as Van Fraassen demands) or is good (in Achinstein's sense) can be put to use in subverting the dynamic and explaining to the explainer. The explainee could disunderstand by responding with "Sure, but why do women care so much about how they look?" which puts the conversation on course to reveal a more overtly sexist belief that may be apt for straightforward negation, or to arrive at the social origins of women's anxieties.

Disunderstanding need not be verbal. It may consist of behaviors that enact a refusal to follow rules that are supported by a widely accepted explanation. Consider Claudette Colvin's and Rosa Parks's deliberate refusals to understand the rules concerning segregated seating on buses, forcing the racist policy into overt discussion. Lawmakers were forced either to attempt to explain their reasoning more forcefully or to change the law. Queering one's performance of gender is also in some cases a deliberate refusal to understand gender essentialism or the sex-gender binary.

It is important to note that the method of resistance I am recommending could be, in a different social context, a harmful practice. Kristie Dotson describes the way in which marginalized speakers discussing their marginalization are often silenced by audiences precisely because successful communication requires "an audience willing and capable of hearing [them]." ${ }^{43}$ If an audience refuses uptake to a speaker because of ignorance (intentional or otherwise) or because the credibility of the speaker has been deflated (i.e., testimonial injustice), an explanation will be blocked in ways that are epistemically and ethically troubling. It is therefore important to specify the scope of disunderstanding, which is intended as a purposeful tool for resisting marginalization, rather than as a way of reinscribing power. It is doubtful that disunderstanding could be successfully misused in this way, since oppressive utterances and actions have a habit of resting on various unstated, harmful assumptions in ways that anti-oppressive expla-

43 Dotson, “Tracking Epistemic Violence, Tracking Practices of Silencing," 238. Similarly, Cull describes "dismissive incomprehension," whereby a listener feigns incomprehension of another person's speech in order to discredit them in the eyes of others. Gaslighting is an extreme form of dismissive incomprehension in which the speaker is made to doubt her own credibility ("Dismissive Incomprehension"). See also Kukla's "discursive injustice" ("Performative Force, Convention, and Discursive Injustice") and Langton's "illocutionary silencing” and "perlocutionary silencing" ("Speech Acts and Unspeakable Acts"). 
nations do not, but the analysis in this paper may shed light on the ways in which something akin to disunderstanding is attempted by those who intend harm.

Of course, a person's ability to resist an explanation, like her ability to resist simpliciter, is critically dependent on her positionality. Those who are most likely to identify the need to resist are also those for whom resistance might turn out to be costliest or most dangerous. Further, due to widespread epistemic prejudices, they are also most likely to be deemed to genuinely misunderstand and require additional instruction from a person who deems himself to have greater expertise. ${ }^{44}$ There is an irony here: disunderstanding often requires that a person who is seen as less knowledgeable perform ignorance in order to force the person who is seen as more knowledgeable to face up to their actual ignorance. These points emphasize the importance of allyship: those who are relatively privileged are best placed to practice disunderstanding in order to erode harmful assumptions and reduce the likelihood that those who are directly affected will encounter them. This requires those with greater comparative privilege (particularly in an epistemic sense) to be continually attentive to the teachings of oppressed people, so that when the moment arises, they will be equipped to sense the underlying assumptions and be prepared to excavate them.

Accepting an explanation that is marginalizing requires that a person revise (or appear to revise) their background assumptions to accommodate content that produces, entrenches, or ignores injustices. Conversely, if a person outwardly refuses to understand, the speech act is thwarted, and the explanatory demand persists, forcing the explainer to more carefully scrutinize their own assumptions in the course of attempting to generate an alternative explanation. Disunderstanding blocks wrongful requests for understanding and can therefore contribute to destabilizing explanatory injustice.

\section{CONCLUSION}

In this paper, I have built on the work of Pohlhaus to show that understanding, which is conferred as a result of successful explanations, is not always ethically and epistemically virtuous. I have formalized a way of refusing to understand by disrupting the successful operation of an oppressive explanation. A successful explanation requires that the explainee's why-question be answered by the perlocutionary act of revision to her background assumptions and that she communicate that success. Importantly, this means that explanations are collaborative, and the explainee plays a critical role in the process of explaining; an explanation is not successful unless an explainee deems it to be so. By feigning misunder-

44 Consider mansplaining. See note 28. 
standing in specific ways, explainees can therefore disrupt oppressive explanations that rely on problematic assumptions and generalizations with false implicatures. As such, there is epistemic and ethical merit in the explainee subverting her expected role as the cooperative recipient of an explanation, in strategically disunderstanding in order to force the conspicuousness and interrogation of marginalizing epistemologies. ${ }^{45}$

Brighton and Sussex Medical School a.shahvisi@bsms.ac.uk

\section{REFERENCES}

Achinstein, Peter. The Nature of Explanation. Oxford: Oxford University Press, 1983.

Anderson, Luvell. "Racist Humor." Philosophy Compass 10, no. 8 (August 2015): 501-9.

Austin, J.L. How to Do Things with Words. 2nd ed. Edited by J. O. Urmson and Marina Sbisà. Oxford: Oxford University Press, 1975.

Bartky, Sandra Lee. Femininity and Domination: Studies in the Phenomenology of Oppression. New York: Routledge, 2015.

Bates, Laura. "A Cycle of Violence: When a Woman's Murder Is Called 'Understandable." Guardian, July 26, 2016.

https://www.theguardian.com/lifeandstyle/womens-blog/2016/jul/26/ womans-murder-called-understandable-lance-hart.

Bergmann, Merrie. "How Many Feminists Does It Take to Make a Joke? Sexist Humor and What's Wrong with It." Hypatia 1, no. 1 (Spring 1986): 63-82.

Camp, Elisabeth. "Insinuation, Common Ground, and the Conversational Record." In New Work on Speech Acts, edited by Daniel Fogal, Daniel W. Harris, and Matt Moss, 40-66. Oxford: Oxford University Press, 2018.

Cimpian, Andrei, Amanda C. Brandone, and Susan A. Gelman. "Generic Statements Require Little Evidence for Acceptance but Have Powerful Implications." Cognitive Science 34, no. 8 (November 2010): 1452-82.

I wish to thank audiences at the Five College Women's Studies Research Center and the Program for the Study of Women and Gender at Smith College, Boston University's Colloquium for the Philosophy of Science, the Decolonising Science Society at King's College London, the CRASSH program at the University of Cambridge, and the 2019 Society of Women in Philosophy's annual conference for their feedback on earlier drafts. I would also like to thank Lisa Armstrong, Chanda Prescod-Weinstein, Kristie Dotson, Martina Rosola, and Neil Singh. 
Cull, Matthew J. “Dismissive Incomprehension: A Use of Purported Ignorance to Undermine Others." Social Epistemology 33, no. 3 (2019): 262-71.

Davidson, Donald. “On the Very Idea of a Conceptual Scheme." In Inquiries into Truth and Interpretation, 183-98. Oxford: Oxford University Press, 2001.

De Regt, Henk W. "Understanding and Explanation: Living Apart Together?" Studies in History and Philosophy of Science Part A 44, no. 3 (September 2013): 505-9.

Dotson, Kristie. "Tracking Epistemic Violence, Tracking Practices of Silencing." Hypatia 26, no. 2 (Spring 2011): 236-57.

Fricker, Miranda. Epistemic Injustice: Power and the Ethics of Knowing. Oxford: Oxford University Press, 2007.

Graham, Susan A., Samantha L. Nayer, and Susan A. Gelman. "Two-Year-Olds Use the Generic/Nongeneric Distinction to Guide Their Inferences about Novel Kinds." Child Development 82, no. 2 (March/April 2011): 493-507.

Haslanger, Sally. "Ideology, Generics, and Common Ground." In Feminist Metaphysics: Explorations in the Ontology of Sex, Gender and the Self, edited by Charlotte Witt, 179-207. Dordrecht: Springer, 2011.

Hempel, Carl G. Aspects of Scientific Explanation and Other Essays in the Philosophy of Science. New York: Free Press, 1965.

Hempel, Carl G., and Paul Oppenheim. "Studies in the Logic of Explanation." Philosophy of Science 15, no. 2 (April 1948): 135-75.

Hornsby, Jennifer. “Disempowered Speech.” Philosophical Topics 23, no. 2 (Fall 1995): 127-47.

Khalifa, Kareem. "Inaugurating Understanding or Repackaging Explanation?” Philosophy of Science 79, no. 1 (January 2012): 15-37.

Kukla, Rebecca. "Performative Force, Convention, and Discursive Injustice." Hypatia 29, no. 2 (Spring 2014): 440-57.

Langton, Rae. "Feminism in Epistemology: Exclusion and Objectification." In The Cambridge Companion to Feminism in Philosophy, edited by Miranda Fricker and Jennifer Hornsby, 127-45. Cambridge: Cambridge University Press, 2000.

- "Speech Acts and Unspeakable Acts." Philosophy and Public Affairs 22, no. 4 (Autumn 1993): 293-330.

Leslie, Sarah-Jane. "The Original Sin of Cognition: Fear, Prejudice, and Generalization.” Journal of Philosophy 114, no. 8 (August 2017): 393-421.

Leslie, Sarah-Jane, and Adam Lerner. "Generic Generalizations." Stanford Encyclopedia of Philosophy (Winter 2016). https://plato.stanford.edu/archives/ win2016/entries/generics/.

Leslie, Sarah-Jane, Sangeet Khemlani, and Sam Glucksberg. "Do All Ducks Lay 
Eggs? The Generic Overgeneralization Effect." Journal of Memory and Language 65, no. 1 (July 2011): 15-31.

Liebow, Nabina. "Internalized Oppression and Its Varied Moral Harms: Self-Perceptions of Reduced Agency and Criminality." Hypatia 31, no. 4 (Fall 2016): 713-29.

Lombrozo, Tania. "Causal-Explanatory Pluralism: How Intentions, Functions, and Mechanisms Influence Causal Ascriptions." Cognitive Psychology 61, no. 4 (December 2010): 303-32.

Manne, Kate. Down Girl: The Logic of Misogyny. Oxford: Oxford University Press, 2017.

Millican, Julie, Christine Schwen, and Justin Berrier. "What Does Brian Kilmeade Have to Say to Get Fired?” Media Matters for America, October 15, 2010. https://www.mediamatters.org/fox-friends/what-does-brian-kilmeade -have-say-get-fired.

Mellor, D. H. "Probable Explanation." Australasian Journal of Philosophy 54, no. 3 (December 1976): 231-41.

Pohlhaus, Gaile, Jr. "Wrongful Requests and Strategic Refusals to Understand." In Feminist Epistemology and Philosophy of Science: Power in Knowledge, edited by Heidi E. Grasswick, 223-40. Netherlands: Springer, 2011.

Prasada, Sandeep, Sangeet Khemlani, Sarah-Jane Leslie, and Sam Glucksberg. "Conceptual Distinctions amongst Generics." Cognition 126, no. 3 (March 2013): 405-22.

Saul, Jennifer. “Are Generics Especially Pernicious?” Inquiry (2017): 1-18.

Shahvisi, Arianne. "Privilege, Platforms, and Power: Uses and Abuses of Academic Freedom." In Enforcing Silence: Academic Freedom, Palestine and the Criticism of Israel, edited by David Landy, Ronit Lentin, and Conor McCarthy, 310-30. London: Zed Books, 2020.

Strevens, Michael. "No Understanding without Explanation." Studies in History and Philosophy of Science Part A 44, no. 3 (September 2013): 510-15.

Van Fraassen, Bas C. The Scientific Image. Oxford: Oxford University Press, 1980. Williams, Patricia. "Spirit-Murdering the Messenger: The Discourse of Fingerpointing As the Law's Response to Racism." University of Miami Law Review 42, no. 1 (1987): 127-57.

YouGov and Arab News. "Uk Attitudes toward the Arab World." 2017. https:// www.arabnews.com/sites/default/files/pdf/topline_pdf_finalx.pdf.

Zheng, Robin. "Attributability, Accountability, and Implicit Bias." In Moral Responsibility, Structural Injustice, and Ethics, edited by Michael Brownstein and Jennifer Saul, 62-89. Vol. 2 of Implicit Bias and Philosophy. Oxford: Oxford University Press, 2016. 